\title{
TEORES DE POLIFENÓIS DE CAULE E FOLHA DE QUATRO CULTIVARES DE ABACAXIZEIRO ${ }^{1}$
}

\author{
MÔNICA ALESSANDRA TEIXEIRA DOS SANTOS ${ }^{2}$, ISMAEL ANTÔNIO DOS SANTOS NEPOMUCENO², \\ CELESTE MARIA PATTO DE ABREU ${ }^{4}$, VÂNIA DÉA DE CARVALHO ${ }^{5}$
}

\begin{abstract}
RESUMO - Teores de polifenóis foram determinados nos resíduos agrícolas - caule e folha -do abacaxizeiro (Ananas comosus (L.) Merrill) das cultivares Pérola, Perolera, Smooth Cayenne e Primavera, cultivadas em Ijací-MG, com o objetivo de subsidiar a possível utilização destes resíduos para consumo humano e/ou animal. De acordo com os resultados obtidos, nenhuma das cultivares estudadas apresentou teores de polifenóis acima de $1 \%$, nível considerado alto e prejudicial à digestibilidade de proteínas. A folha apresentou teores de polifenóis superiores aos do caule em todas as cultivares analisadas. Não houve diferenças significativas entre as cultivares, mas a Smooth Cayenne e a Perolera apresentaram os maiores e menores teores de polifenóis, respectivamente.
\end{abstract}

Termos para indexação: Ananas comosus (L.) Merrill, folhas, caules, cultivares, polifenóis

\section{STEM AND LEAF POLYPHENOLS CONTENTS OF FOUR PINEAPPLE CULTIVARS}

\begin{abstract}
In this study were determined the polyphenols contents of agricultural residues - stem and leaf - of pineapple plants (Ananas comosus (L.) Merrill) from the cultivars Pérola, Perolera, Smooth Cayenne and Primavera, grown in Ijací, MG, with the purpose of giving information on the possible use of these residues as human and/or animal food. The cultivars studied did not present polyphenols contents above $1 \%$, level considered high and harmful to the protein digestibility. The leaves presented polyphenols contents higher than stems in all cultivars analysed. There were no significant differences among cultivars, but Smooth Cayenne had the highest polyphenols contents and Perolera the lowest.
\end{abstract}

Index terms: Ananas comosus (L.) Merrill, stems, leaves, cultivars, polyphenols

Cultivado principalmente nas regiões tropicais e subtropicais, o abacaxi ocupa uma posição de destaque na produção brasileira e o segundo lugar na produção mundial. Em 1998, o Estado de Minas Gerais contribuiu com a abacaxicultura nacional, ocupando o primeiro lugar em área plantada e o segundo em produção, perdendo apenas para o Estado da Paraíba (Souza et al., 1999).

Segundo Carvalho (1985), apenas $22,5 \%$ do abacaxizeiro é aproveitado, correspondente à parte comestível e industrializável. Do restante, $4,5 \%$ constituem a casca do fruto e $73 \%$ a parte vegetativa (folhas, caule, coroa), considerados resíduos agrícolas. Portanto, um dos problemas da cultura do abacaxi é o alto percentual destes resíduos - soqueiras - que se apresentam como foco de pragas e doenças à cultura (Couto, 1985).

Dados sobre alimentos não convencionais têm sido encontrados na literatura (Botelho, 1998; Pinto, 1998; Sartorelli, 1998; Santos, 2000), e o resíduo do abacaxizeiro pode ter um papel importante em dietas balanceadas. Sabe-se que a parte vegetativa do abacaxizeiro é ricamente constituída de carboidratos, proteínas, enzimas proteolíticas (bromelinas) e fibras. Entretanto, os vegetais têm a capacidade de sintetizar uma complexidade de compostos químicos que podem acarretar reações tóxicas quando ingeridos pelo homem ou animais (Pinto, 1998). Muitos alimentos contêm substâncias que são prejudiciais se consumidas em quantidades suficientes para produzir efeitos antinutricionais ou tóxicos. Segundo Grupta et al. (1989), é essencial o estudo dos fatores antinutricionais e/ou tóxicos dos vegetais de uso convencional e não convencional, na alimentação humana e animal.

Os polifenóis fazem parte da composição de muitas plantas e são considerados fatores antinutricionais de grande importância. São substâncias quimicamente muito ativas e que podem reagir, reversível ou irreversivelmente, com proteínas, prejudicando a digestibilidade e a biodisponibilidade da lisina e de outros aminoácidos essenciais. As substâncias fenólicas mais encontradas em plantas são: ácidos fenólicos, flavonóides e taninos. Os polifenóis do tipo tanino possuem a importante característica de se ligar às proteínas (Butler, 1989) e, de acordo com Maliwal (1983), formam complexos proteína-tanino mediante pontes de hidrogênio, impedindo assim a digestibilidade das mesmas. Segundo Chung et al. (1998), além das proteínas, os taninos formam complexos com o amido e enzimas digestivas, reduzindo o valor nutricional dos alimentos. São atribuídos aos taninos outros efeitos prejudiciais à dieta, como cor indesejável aos alimentos e rações e diminuição da palatabilidade, devido à

1 Trabalho $\mathrm{n}^{\circ}$ 139/2000. Recebido: 13/07/2000. Aceito para publicação: 17/07/2001.

2 Zootecnista- Mestre em Ciência dos Alimentos pela Universidade Federal de Lavras (UFLA), Lavras, MG.

3 Estudante de Agronomia- Estagiário do Departamento de Ciência dos Alimentos, Universidade Federal de Lavras (UFLA), Lavras, MG.

4 Eng $^{\mathrm{a}}$. Agr ${ }^{\mathrm{a}}$., DS. Ciência dos Alimentos, Prof ${ }^{\mathrm{a}}$. Adjunta do Departamento de Química, Universidade Federal de Lavras (UFLA), Lavras, MG.

5 Eng $^{\mathrm{a}}$. Agra ${ }^{\text {. }, ~ D S . ~ C i e ̂ n c i a ~ d o s ~ A l i m e n t o s, ~ P r o f ~}{ }^{\mathrm{a}}$. Adjunta do Departamento de Ciência dos Alimentos, Universidade Federal de Lavras (UFLA), Lavras, MG. 
TABELA 1 - Teores médios de polifenóis na matéria seca de folhas e caules de quatro cultivares de abacaxizeiro. Ijaci, 2000.

\begin{tabular}{lccc}
\hline & \multicolumn{3}{c}{ Polifenóis totais $(\mathrm{g} / 100 \mathrm{~g})^{1}$} \\
\cline { 2 - 4 } Cultivares & Folha & Caule & M édias \\
\hline Smooth Cayenne & 0,808 a A & 0,609 a B & 0,708 \\
Primavera & $0,719 \mathrm{~b} \mathrm{~A}$ & 0,607 a B & 0,663 \\
Pérola & $0,770 \mathrm{ab} \mathrm{A}$ & $0,550 \mathrm{ab} \mathrm{B}$ & 0,660 \\
Perolera & $0,782 \mathrm{ab} \mathrm{A}$ & $0,530 \mathrm{~b} \mathrm{~B}$ & 0,656 \\
\hline M édias & $0,770 \mathrm{~A}$ & $0,574 \mathrm{~B}$ &
\end{tabular}

Médias seguidas da mesma letra minúscula, nas linhas, e da mesma letra maiúscula, nas colunas, não diferem entre si, pelo teste de Tukey (P>0,05)

adstringência.

Considerando a grande quantidade de soqueira produzida na abacaxicultura e sabendo-se da importância do estudo de fatores antinutricionais, particularmente compostos polifenóis, objetivou-se determinar os teores de polifenólicos em caules e folhas de quatro cultivares do abacaxizeiro.

Foram utilizados caules e folhas do abacaxizeiro das cultivares Pérola, Perolera, Smooth Cayenne e Primavera do município de Ijaci/MG. Para cada cultivar, foram colhidas 100 plantas da soca, cerca de 3 meses após a colheita dos frutos do primeiro ciclo e selecionados 8 grupos de 10 plantas, considerados repetições. No laboratório de Ciência dos Alimentos da Universidade Federal de Lavras, em Lavras/MG, os caules e folhas das plantas foram separados, secos em estufa a $60{ }^{\circ} \mathrm{C}$, triturados em moinho de facas e homogeneizados.

Para a extração dos polifenóis, as amostras homogeneizadas foram submetidas a três fervuras de 15 e 30 minutos para folha e caule, respectivamente. O método de extração utilizado foi o de Swain e Hillis (1959), utilizando metanol (50\%) como extrator. A dosagem foi feita de acordo com o método de Folin-Denis (AOAC, 1990).

$\mathrm{O}$ delineamento experimental foi o inteiramente casualizado, em esquema fatorial $(2 \times 4)$, sendo 2 tipos de materiais (folha e caule) e 4 cultivares (Pérola, Perolera, Smooth Cayenne e Primavera), e 8 repetições, constando, cada unidade experimental, de 10 plantas.

A cultivar Smooth Cayenne apresentou os teores de polifenóis mais altos, tanto nas folhas quanto nos caules, com $0,81 \%$ e $0,61 \%$, respectivamente. Os menores teores de polifenóis foram encontrados nas cultivares Primavera e Perolera, com $0,72 \%$ (folha) e $0,53 \%$ (caule), respectivamente.

Hoseney et al. (1981) relataram que teores superiores a $1 \%$ de taninos são considerados altos e prejudiciais à digestibilidade de proteínas. Segundo revisão realizada por Chung et al. (1998), níveis de tanino de 0,5 a 2\% em rações de aves causaram decréscimo no crescimento e na produção de ovos. Resultados semelhantes foram observados em pintos alimentados com níveis de tanino na ração variando de 0,64 a $0,84 \%$, ocorrendo mortalidade quando esses níveis foram aumentados para 3\%. Rodrigues (1991), estudando taninos em sorgo, extraídos com metanol a $50 \%$, encontrou valores de $0,60 \%$ a $2,61 \%$ na matéria seca, sendo que a folha superou o caule quanto aos teores de polifenóis. No abacaxizeiro, caule e folha apresentaram baixos teores de taninos, não ultrapassando $1 \%$, o que afeta pouco a digestibilidade e biodisponibilidade de alguns aminoácidos essenciais. Como no sorgo, as folhas mostraram teores mais altos de polifenóis que os caules em todas as cultivares de abacaxi estudadas.

De acordo com os dados obtidos, pôde-se concluir que os teores de polifenóis no caule e folhas de abacaxizeiros, cultivares Pérola, Perolera, Smooth Cayenne e Primavera, foram inferiores a $1 \%$, nível considerado não prejudicial à digestibilidade protéica. As folhas apresentaram teores totais de polifenóis superiores aos dos caules, nas quatro cultivares.

\section{REFERÊNCIAS BIBLIOGRÁFICAS}

ASSOCIATION OF OFFICIAL ANALITYCAL CHEMISTS, AOAC. Official Methods of Analysis, 15 ed. Washington, 1990. v.2.

BOTELHO, L. Avaliação química da casca e cilindro central do abacaxi (Smooth cayenne), visando ao seu aproveitamento na alimentação humana. 1998, 63f. Dissertação (Mestrado em Ciência dos Alimentos) - Universidade Federal de Lavras, Lavras, 1998.

BUTLER, L.G. New perspective on the antinutritional effects of tannins. In: KINSELLA, J.E.; SOUCIE, B. Food products. Champaing: American Oil Chemistry Society, 1989. Cap. 22, p. 402-409.

CHUNG, K.T.; WONG, T.Y.; WEI, C.I.; HUANG, Y.W.; LIN, Y. Tannins and human health: a review. Critical Reviews in Food Nutrition, Amherst, v.38, n.6, p.421-464, 1998.

CARVALHO, V.D. Utilização dos resíduos agrícolas do abacaxizeiro. Informe Agropecuário, Belo Horizonte,v.11, n.130, p.73-76, 1985.

COUTO, F.A..A.. Aspectos tecnológicos da abacaxicultura mineira. Informe Agropecuário, Belo Horizonte, v.11, n.130, p.8-12, 1985.

GRUPTA, K.; BARAT, G.K.; WAGLE, D.S.; CHAWLA, H.K.L. 
Nutrient contents and antinutritional factors in conventional and non-conventional leaffy vegetable. Food Chemistry, Oxford, v. 2 , n.31, p.105-116, 1989.

HOSENEY, R.C.; VARRIANO-MARSTON, E.; DENDY, D.A..V. Sorghum and millets. Advances in Cereal Science and Technology, Saint Paul, v.4, p. 71-144, 1981.

MALIWAL, B.P. In vitro methods to assess the nutritive value of leaf protein concentrate. Journal of Agriculture and Food Chemistry, Washington, v.31, n.2, p. 315-319, 1983.

PINTO, N.A..V.D. Avaliação química das folhas, limbos e caules da taioba (Xanthosoma sagittifolium Schott), visando ao seu aproveitamento na alimentação humana. 1998. 88f. Dissertação (Mestrado em Ciência dos Alimentos) - Universidade Federal de Lavras, Lavras, 1998.

RODRIGUES, W.A. Variabilidade para teor de tanino em sorgo (Sorghum bicolor, L.), seu controle genético e associação com a resistência a pássaros. 1991, 72f. Dissertação (Mestrado em Engenharia Agrícola) - Universidade Federal de Lavras, Lavras, 1991.
SANTOS, M.A.T. Caracterização química das folhas de brócoli e couve-flor (Brassica oleracea $\mathrm{L}$.) para utilização na alimentação humana. 2000. 96f. Dissertação (Mestrado em Ciência dos Alimentos) - Universidade Federal de Lavras, Lavras, 2000.

SARTORELLI, C.S.C. Caracterização química da parte aérea de cenoura (Dacus carota) e beterraba (Beta vulgaris), visando ao aproveitamento na alimentação humana. 1998. 98p. Dissertação (Mestrado em Ciência dos Alimentos) Universidade Federal de Lavras, Lavras, 1998.

SOUZA, J.S.; CARDOSO, C.E.L.; TORRES FILHO, P. Situação da cultura no mundo e no Brasil e importância econômica. In: CUNHA, G.A.P.; CABRAL, J.R.S.; SOUZA, L.F.S. O abacaxizeiro: cultivo, agroindústria e economia. Brasília: EMBRAPA, 1999. cap. 16, p.403-428

SWAIN, T.; HILLIS, W.G. The phenolic constituents of Prunus domestica. The quantitative analysis of phenolic constituents. Journal Science Food Agriculture, Chichester, v.10, p.63-68, 1959. 